later when the uterus was replaced the second time. In both cases the child did well.

\section{A FATAL CASE OF ENDOCARDITIS IN A YOUNG CHILD.}

By JohN O. Symes, M.D. Lond., D.P.H., ASSISTANT PHYSICIAN AND BACTERIOLOGIST, BRISTOL GENERAL HOSPITAL.

ENDOCARDITIS is a rare condition in children under two years of age unless it be of congenital origin or consequent upon some infective fever. Dr. J. F. Goodbart and Dr. G. F. Still record that of 169 cases of endocarditis in children only 16 were under four years of age, and of these 12 were probably congenital. I have therefore thought that the following case is worthy of record.

The patient was a girl, aged two years, who attended the out-patient department of the Bristol General Hospital on June 27th, 1905, and was said by her parents to have been ailing since an attack of vomiting and diarrhoa 14 days previously. Although this attack had passed off the child was left pale and so weak that she could hardly walk; they thought, too, that she was wasting. There was no history of previous illness except some enlargement of the cervical glands six months previously. A loud systolic bruit was audible at the heart's apex and was conducted in all directions. The child was admitted to the hospital on July 4th. She was markedly anæmic and thin, the respiration was rapid, and there was orthopnœea. The apex beat was in the fifth and sixth spaces in the nipple line, the left border of the heart was one inch outside the nipple line, and the right border was at the mid-sternum. At the apex the first and second sounds were audible and a loud systolic bruit was carried out to the axilla and heard over the back. The pulse-rate was 136 and the respiration rate was 68. Both liver and spleen were just palpable beneath the costal margin. There were shotty lymph glands in the triangles of the neck, the axilla, and the popliteal spaces. The temperature was subnormal. Examination of the blood showed that a cubic millimetre contained 4,800,000 red cells and 44,000 white ones; the hæmoglobin was 70 per cent. During the six weeks of the child's stay in hospital her condition gradually became weaker and the heart's action and respiration more rapid. She died on August 10th. There were never any signs of arthritis, of hæmorrhage into the skin, or of rheumatic nodules. The temperature never reached $100^{\circ} \mathrm{F}$. until August 7th and 8th (i.e., two days before death), when it rose to $101 \cdot 6^{\circ}$ each evening; morning temperatures of $96.8^{\circ}$ were recorded on July $28 \mathrm{th}$ and August 1st and 7th, but the usual daily range was between $97 \cdot 8^{\circ}$ and $99 \cdot 6^{\circ}$. The pulse-rate varied between 130 and 160 and the respirations between 50 and 70 per minute.

A post-mortem examination showed that the edges of the mitral valve were studded with recent minute vegetations. The wall of the left ventricle was hypertrophied and the chamber dilated. There were no suppurative foci found throughout the body. A stained section of a fragment of the mitral valve showed the vegetations to be crowded with a diplo-streptococcus both on the free surface and on the deeper parts. The organism was larger than any specimens of the diplococcus rheumaticus that $I$ have seen. It retained the stain if treated by Gram's method. Unfortunately, I left Bristol on the day following the post-mortem examination and consequently did not see the cultures prepared from the spleen. The naked-eye appearances were those of rheumatic endocarditis and the hypertrophy of the left ventricle would indicate that this must have been of longer duration than might have been supposed from the history supplied by the parents. Although the rapidly fatal termination of the case suggested a malignant endocarditis, yet no septic focus could be discovered nor were large vegetations, or ulceration of the mitral valves, or infarcts in organs found at the post-mortem examination.

Clifton, Bristol.

Penalty Incurred by a Water Company. - The Tredegar (Monmouthshire) bench of magistrates imposed a penalty of $£ 100$, with 30 guineas costs, upon a water company which neglected to supply water to ten houses at Aberbargoed.

\section{attledical Sotretìes.}

Glasgow Obstetrical and Gyn decological SocIETY.-A meeting of this society was held on May 23rd, Dr. J. K. Kelly, the President, being in the chair.-The following specimens were shown:-Dr. J. Nigel Stark: Abscess in the Ovary, the Tube not being affected; Adhesions to the Crecum and Appendix.-Dr. Russell: (1) A Large Fibroid of the Uterus removed for severe hæmorrhage; (2) Multiple Fibroids of the Uterus removed for pain; and (3) Multiple Fibroids of the Uterus with Adherent Tubes and Ovaries.-Dr. J. M. Munro Kerr: (1) A Large Unilocular Cyst complicating Pregnancy; and (2) Tubal Pregnancy, the tube being unruptured.-The President: A Sarcomatous Tumour of the Uterus with early Pregnancy. The President and Dr. A. Louise McIlroy gave notes, with lantern and microscopic demonstration of a case of Pregnancy occurring in a Graafian Follicle. A brief outline of the literature of ovarian pregnancy was given, with a short description of the best known cases, including those of Koumer, van Tussenbroeck, Thompson, Mendes de Léon, Holleman, and the latest one by Freund and Thomé. In the present case the patient, aged 33 years, had been married for 12 years and had had five children, the last one being born two and a half years before she came under observation. She was admitted to the Glasgow Royal Infirmary on Jan. 25th, 1905. She had had an attack of severe pain in both iliac regions in the beginning of December, 1904, after a period of six weeks' amenorrhcea; this pain was followed by a hæmorrhagic discharge from the uterus which lasted for three days and then returned in four days, lasting that length of time. The discharge returned in a fortnight and was present when the patient was admitted to the infirmary. On examination there was found to be tenderness over the left iliac region but no tumour was felt. Per vaginam the cervix proved to be in the ordinary situation, the uterus to be normal in position and somewhat enlarged, and the left appendages which formed a considerable mass were tender to pressure. Extra-uterine pregnancy was diagnosed but as there was no hæmatocele operation was delayed for some days. As the discharge still continued the abdomen was opened on Feb. 6th and a small blood cyst was found in the left ovary; this was removed with the tube. On the right side the adnexa were normal. No blood was found in the peritoneal cavity. Recovery was uninterrupted. The specimen was of the size of a Victoria plum. In the upper part was the normal ovarian tissue, pale in colour; the lower part was rough and deeply stained with hæmorrhage. The tube and mesosalpinx were normal. Subsequent microscopical examinations of the tube showed normal ciliated epithelium. The blood mass in the ovary was divided into two parts and one portion was cut into sections and examined under the microscope. No embryo was found. The ovum was discovered to be imbedded inside a Graafian follicle, the walls of which were found to contain lutein tissue. The walls of the ovisac were much thinned out in the lower portion of the specimen where rupture would have taken place later. Strands of amnion and chorion were found in the blood mass with degenerated chorionic villi. In some places masses of trophoblast were seen in contact with the layer of canalised fibrin. Masses of syncytial cells were also seen in the blood clot. The ovum had been imbedded on a layer of connective tissue inside the lutein cell layer; nowhere were decidual cells found. The whole ovum was completely surrounded by ovarian tissue which contained follicles in its substance in the upper portion. Two corpora lutea were found in the ovarian tissue. The illustrations comprised drawings of the specimen before cutting into the interior and also sections of villi in the centre of the blood mass and lying on fibrin layers, \&c.Dr. John Lindsay said that this was the first case published in Scotland and was therefore of great interest to the society. - Dr. Munro Kerr had had a similar case two and a half zears ago but had not as yet fully published it; his specimen was shown at the Eidinburgh Obstetrical Society and had been seen by several eminent gynæcologists since. The patient had had symptoms of extra-uterine pregnancy with severe pain, and intra-uterine pregnancy was also present. At the operation an enlarged ovary was found with tube intact; the uterus was enlarged and soft. The patient was delivered at full term of a healthy child. The specimen showed a six weeks pregnancy, the ovam being imbedded 